\title{
HEALTH EDUCATION TERHADAP PENGETAHUAN IBU HAMIL TENTANG TERAPI SITZ BATH DI WILAYAH KERJA PUSKESMAS BALONG PONOROGO
}

\author{
Ambika Kurnia Mustikawati ${ }^{1)}$, Rindang Fitria Ulfa ${ }^{2)}$ \\ Akbid Harapan Mulya Ponorogo ${ }^{1,2)}$ \\ ambikadirham06@gmail.com ${ }^{1)}$, rindang.fitrianaulfa1992@gmail.com ${ }^{2)}$
}

\begin{abstract}
Haemorrhoids are common in pregnant women in the second or third trimester of pregnancy. Increased intra-pressure due to fetal growth and changes in the hormone progesterone causes the hemorrhoidal veins to become wide. Pregnancy hemorrhoids are temporary hemorrhoids which means they will disappear some time after delivery, but can cause a very uncomfortable feeling, itching around the anus and even bleeding during bowel movements. Therefore, self care is needed, one of them is the sitz bath method.The design in this study is a pre-experiment with the One Group Pretest-Posttest design approach. The population in this study were all mothers with hemorrhoids who participated in the pregnant class at Balong Health Center for the period of 1-28 February 2020, a total of 37 people. The sampling method used accidental sampling of 31 people. Instrument with quesioner. Statistical test using the Wilcoxon Signed-Rank Test with $\alpha=0.05$. The result of knowledge of mothers about Sitz Bath Therapy in the Work Area of Puskesmas Balong, Ponorogo Regency, before health education was carried out, most of them were 16 respondents (51.6\%) had sufficient knowledge and after health education was carried out most of them 18 respondents (58.1\%) had good knowledge. There is an effect of health education on maternal knowledge about Sitz Bath Therapy in the working area of Health Center Balong, Ponorogo with a p value of $0.000 \leq \alpha 0.05$. The role of health workers as educators is better to carry out routine health education during the provision of care, especially regarding the method of sitz bath therapy so that targets can better understand and be able to overcome hemorrhoid problems that occur in pregnancy.
\end{abstract}

Keywords : health education, pregnancy, sitz bath

\section{LATAR BELAKANG}

Hemoroid atau wasir atau yang biasa disebut ambeien oleh masyarakat merupakan pelebaran dan inflamasi pembuluh darah vena di daerah anus yang berasal dari plexus hemorrhoidalis. Hemorrhoid merupakan suatu penyakit yang dapat mengganggu aktivitas sehari-hari sehingga mengakibatkan penurunan kualitas hidup seseorang. Hemorrhoid juga cenderung memburuk dari tahun ke tahun (Sudoyo, 2006).

Hemoroid merupakan penyebab umum dari perdarahan rektum dan ketidaknyamanan anal. Hemoroid diderita oleh 5\% seluruh penduduk dunia (Slavin, 2008). Insiden hemoroid terjadi pada13\%$36 \%$ populasi umum di Inggris (Lohsiriwat, 2012). Berdasarkan data dari The National Center of Health Statistics di Amerika 


\section{Jurnal Delima Harapan 2021}

Serikat, prevalensi hemoroid sekitar 4,4\% (Buntzen et al., 2013).

Hemoroid biasa terjadi pada wanita hamil pada trimester dua atau ketiga kehamilan. Peningkatan tekanan intra karena pertumbuhan janin serta adanya perubahan hormone progesteron menyebabkan vena hemoroidalis menjadi lebar. Selain itu progesteron juga ikut berkontribusi pada sembelit dengan memperlambat gerakan di usus. Hemoroid kehamilan merupakan hemoroid temporer yang berarti akan hilang beberapa waktu setelah melahirkan. Walaupun keadaan ini tidak mengancam jiwa, tetapi dapat menyebabkan perasaan yang sangat tidak nyaman, gatal di sekitar anus bahkan perdarahan saat BAB. Pada kondisi ini diperlukan perawatan sendiri dan gaya hidup sehat (Sjamsuhidayat, 2004).

Ibu yang sudah pernah mengalami ambeien saat hamil sebelumnya memungkinkan untuk mengalaminya lagi saat hamil berikutnya. pada ibu hamil dengan sembelit atau yang sering berdiri terlalu lama. Hal tersebut dapat meningkatkan tekanan pada pembuluh darah anus, sehinga terjadi ambeien. Kadang kala ambeien hanya menimbulkan rasa gatal, sering kali penyakit ini terasa menyakitkan. Bahkan mungkin saja menyebabkan perdarahan di dubur, yaitu ketika sedang buang air besar (Trottier M, 2012).

Berdasarkan study kasus yang dilakukan di kelas hamil Puskesmas Balong Kabupaten Ponorogo pada Januari 2020, melalui wawancara pada 10 orang ibu hamil, 7 diantara mengatakan mengalami wasir di sekitar anus. 4 diantaranya mengalami BAB yang disertai darah dan 4 diantaranya mengalami rasa yang tidak nyaman serta gatal disekitar anus. Ibu hamil tersebut mengatakan khawatir dengan kondisinya dan takut hal ini akan mempengaruhi kondisi janinnya.

Hemorhoid pada wanita hamil biasanya cukup diatasi dengan laksatif, pelunak feses, dan sitz baths. Hemorhoid yang mengalami trombosis dapat diatasi dengan cara eksisi. Namun, pada beberapa kasus, hemorrhoid dalam kehamilan membutuhkan tindakan operatif apabila hemorrhoid tersebut menimbulkan komplikasi. Setelah melahirkan, hemorrhoid yang tanpa komplikasi berat akan mengecil dengan sendirinya. Hemorhoid yang mengalami trombosis dapat diatasi dengan cara eksisi. Namun, pada beberapa kasus, hemorrhoid dalam kehamilan membutuhkan tindakan operatif apabila hemorrhoid tersebut menimbulkan komplikasi. Tatalaksana hemorrhoid terdiri dari terapi non bedah dan terapi bedah. Hemorhoid pada wanita hamil biasanya cukup diatasi dengan laksatif, pelunak feses, dan sitz baths (Khairani, 2014).

Terapi Sitz Bath meliputi perendaman bagian perineum dalam air hangat atau panas untuk mengurangi ketidaknyamanan serta meningkatkan proses kesembuhan luka dengan cara membersihkan perineum dan anus yang akan membantu meningkatkan sirkulasi darah serta mengurangi inflamasi selama 15-30 menit. Sitz Bath dilakukan dilakukan 2 kali dalam 1 hari. Pada hari yang sama satu kali di siang hari dan malamnya satu kali, karena akan terlihat perubahannya jika dibandingkan hanya satu kali. Satu kali sesi terdiri dari alternatif air hangat dan air dingin dengan pengukuran waktu selama 12 menit. Dalam 12 menit terdiri dari 3 siklus, yaitu 2 menit dalam air hangat dan lalu di ganti dengan air dingin, 


\section{Jurnal Delima Harapan 2021}

diulangi sampai 3 kali atau tergantung dengan tingkat keparahan penyakit (Lockhart dkk, 2014).

Komplikasi dari hemorrhoid yang paling sering adalah perdarahan, trombosis dan strangulasi. Yang lebih sering terjadi yaitu perdarahan kronis dan apabila berulang dapat menyebabkan anemia karena jumlah eritrosit yang diproduksi tidak dapat mengimbangi jumlah darah yang keluar. Anemia terjadi secara kronis, sehingga sering tidak menimbulkan keluhan pada penderita, walaupun kadar hemoglobin sangat rendah karena adanya mekanisme adaptasi. Keadaan trombosis dapat menyebabkan nyeri yang hebat dan dapat menyebabkan nekrosis mukosa dan kulit yang menutupinya sehingga mudah terjadi infeksi yang dapat menyebabkan sepsis dan bisa mengakibatkan kematian.

Peningkatan pengetahuan dapat dilakukan dengan peningkatan pendidikan, pelatihan, health education, dan informasi melalui media massa dan elektronik. Health education yang dilakukan dengan penyebaran pesan dan mennamkan keyakinan akan membuat ibu tidak saja sadar, tahu dan mengerti tetapi juga mau dan bisa melakukan suatu anjuran yang ada hubungannya dengan kesehatan (Machfoedz, dkk, 2005). Diharapkan health education meningkatkan pengetahuan dan kemampuan ibu dalam penggunaan terapi Sitz Bath untuk meringankan gejala hemoroid sehingga mengurangi ketidaknyamanan yang terjadi.

Health education keapada ibu hamil tentang terapi Sitz Bath diharapkan dapat diterapkan dalam kehidupan sehari-hari. Kegiatan health education berupa penyuluhan merupakan salah satu tugas tenaga kesehatan terutama bidan sebagai pendidik yaitu memberikan promosi kesehatan kepada ibu hamil sehingga meningkatkan pengetahuan dan membantu meningkatkan kualitas hidupnya.

\section{METODE PENELITIAN}

Desain pada penelitian ini yaitu preeksperiment dengan pendekatan rancangan One Group Pretest-Posttest dalam rancangan ini tidak ada kelompok pembanding (kontrol), tetapi paling tidak sudah dilakukan observasi pertama (Pretest) yang memungkinkan peneliti dapat menguji perubahan-perubahan yang terjadi setelah adanya perlakuan (eksperimen). Populasi pada penelitian ini yaitu seluruh ibu dengan hemoroid yang mengikuti kelas hamil di Puskesmas Balong periode 1 Februari-28 Februari 2020 sejumlah 37 orang. Metode pengambilan sampel menggunakan accidental sampling. Instrumen yang digunakan dengan kuesioner. Uji statistik menggunakan Wilcoxon Signed-Rank Test dengan $\alpha=0,05$

\section{HASIL PENELITIAN}

1. Pengetahuan Ibu tentang Terapi Sitz Bath sebelum dilakukan health education

Tabel 1. Distribusi Frekuensi

Pengetahuan Ibu Tentang Terapi Sitz Bath Sebelum Dilakukan Health Education

\begin{tabular}{|c|c|c|c|}
\hline No & Pengetahuan & Frekuensi & $(\%)$ \\
\hline 1 & Kurang & 12 & 38,7 \\
\hline 2 & Cukup & 16 & 51,6 \\
\hline 3 & Baik & 3 & 9,7 \\
\hline & Jumlah & 31 & 100 \\
\hline
\end{tabular}

Page 42 


\section{Jurnal Delima Harapan $\mathbf{2 0 2 1}$}

yaitu 16 responden $(51,6 \%)$ mempunyai pengetahuan cukup.

2. Pengetahuan Ibu tentang Terapi Sitz Bath setelah dilakukan health education

Tabel 2. Distribusi Frekuensi Pengetahuan Ibu Tentang Terapi Sitz Bath Setelah Dilakukan Health Education

\begin{tabular}{cccc}
\hline No & Pengetahuan & Frekuensi & $\mathbf{( \% )}$ \\
\hline 1 & Kurang & 2 & 38,7 \\
2 & Cukup & 11 & 51,6 \\
3 & Baik & 18 & 9,7 \\
\hline & Jumlah & 31 & 100 \\
\hline
\end{tabular}

Berdasarkan tabel diatas dari 31 responden didapatkan sebagian besar yaitu 18 responden $(58,1 \%)$ mempunyai pengetahuan baik.

3. Pengaruh health education terhadap pengetahuan ibu hamil tentang terapi sitz bath di Wilayah Kerja Puskesmas Balong Kabupaten Ponorogo

Tabel 3. Distribusi Frekuensi Pengetahuan Ibu Tentang Terapi Sitz Bath Sebelum Dilakukan Health Education

\begin{tabular}{|c|c|c|c|c|}
\hline \multirow{2}{*}{$\begin{array}{c}\text { Pengetah } \\
\text { uan }\end{array}$} & \multicolumn{3}{|c|}{ Sesudah } & $\Sigma$ \\
\hline & Kurang & Cukup & Baik & \\
\hline Kurang & 2 & 8 & 2 & 12 \\
\hline Cukup & 0 & 3 & 13 & 16 \\
\hline Baik & 0 & 0 & 3 & 3 \\
\hline Jumlah & 2 & 11 & 18 & 31 \\
\hline $\begin{array}{l}\quad \text { Berda } \\
\text { didapatk } \\
\text { responde } \\
\text { health } \\
\text { pengetah } \\
\text { health ea }\end{array}$ & $\begin{array}{l}\text { asarkan } \\
\text { an hamp } \\
\text { en }(41,9 \\
e d u \\
\text { uan cuk } \\
\text { ducation }\end{array}$ & $\begin{array}{l}\text { tabul } \\
\text { ir setenga } \\
\% \text { ) sebel } \\
\text { ation } \\
\text { up dan set } \\
\text { berpenget }\end{array}$ & $\begin{array}{l}\text { nya y } \\
\text { n dil } \\
\text { mem }\end{array}$ & $\begin{array}{l}\text { silang } \\
\text { itu } 13 \\
\text { kukan } \\
\text { ounyai } \\
\text { kukan } \\
\text { iik. }\end{array}$ \\
\hline
\end{tabular}

Volume 8 Nomor 2 September 2021
Tabel 4. Hasil Wilcoxon Signed Ranks Test

\begin{tabular}{cl}
\hline & POST-PRE \\
\hline$Z$ & $-4,630$ (a)
\end{tabular}

\begin{tabular}{ll} 
Asymp. Sig. (2-tailed) &, 000 \\
\hline Output SPSS, pada taraf signifikan
\end{tabular} $95 \%(\alpha=0,05), \quad p$-value atau Sig. (2tailed) pada tabel Wilcoxon Signed Ranks Test adalah 0,000 yang mana angka ini lebih kecil dari $\alpha=0,05(0,000 \leq 0,05)$ yang artinya ada pengaruh health education terhadap pengetahuan ibu hamil tentang terapi sitz bath.

\section{PEMBAHASAN}

Berdasarkan tabulasi silang didapatkan hamper setengahnya yaitu 13 responden $(41,9 \%)$ sebelum dilakukan health education pengetahuan cukup dan setelah dilakukan health education berpengetahuan baik. Output SPSS, pada taraf signifikan 95\% $(\alpha=0,05), p$-value atau Sig. (2-tailed) pada tabel Wilcoxon Signed Ranks Test adalah 0,000 yang mana angka ini lebih kecil dari $\alpha=0,05(0,000 \leq 0,05)$ yang artinya ada pengaruh health education terhadap pengetahuan ibu hamil tentang terapi sitz bath di Wilayah Kerja Puskesmas Balong Kabupaten Ponorogo.

Manusia mempunyai dorongan dasar ingin mengetahui, untuk mencari penalaran dan untuk mengorganisasikan pengalamannya. Pemberian informasi adalah pembelajaran kepada masyarakat agar mau melakukan tindakan untuk memelihara kesehatan beserta mengatasi masalahnya. Perubahan atau peningkatan kesehatan dihasilkan oleh pemberian informasi didasarkan kepada pengetahuan dan 


\section{Jurnal Delima Harapan 2021}

kesadarannya melalui proses pembelajaran (Notoadmojo, 2003).

Hemorhoid sering keluar darah dari duburnya namun tidak akan menularkan penyakit pada janin karena hemorrhoid sama sekali tidak berhubungan langsung dengan janin yang keluar dari vagina. Ibu akan mengalami ketidaknyamanan sehingga aktivitas sehari-hari menjadi terganggu dan tidak menjalani kehamilannya dengan nyaman akibat perih yang dia rasakan. Bahaya hemorrhoid pada wanita hamil adalah timbulnya perdarahan yang bisa mengakibatkan anemia. Tetapi hemorrhoid bukan penghalang bagi ibu hamil yang ingin melahirkan normal. Pada kebanyakan wanita, hemorrhoid yang disebabkan oleh kehamilan merupakan hemorrhoid temporer, yang berarti akan hilang beberapa saat setelah melahirkan (Khairani, 2014).

Alternatif tanpa obat yang dapat dilaukan yaitu dengan terapi Sitz Bath. Terapi Sitz Bath meliputi perendaman bagian perineum dalam air hangat atau panas untuk mengurangi ketidaknyamanan serta meningkatkan proses kesembuhan luka dengan cara membersihkan perineum dan anus yang akan membantu meningkatkan sirkulasi darah serta mengurangi inflamasi selama 15-30 menit (Lockhart dkk, 2014).

Seseorang yang tidak mempunyai pengetahuan akan berakibat tidak mempunyai landasan dalam bertindak, karena perilaku yang didasari oleh pengetahuan akan lebih langgeng dari pada perilaku yang tidak didasari oleh pengetahuan. Peningkatan pengetahuan dapat dilakukan dengan peningkatan pendidikan, pelatihan, health education dan informasi melalui media massa dan elektronik. Health Education yang dilakukan dengan penyebaran pesan dan menanamkan keyakinan akan membuat ibu hamil tidak saja sadar, tahu dan mengerti tetapi juga mau dan bisa melakukan suatu anjuran yang ada hubungannnya dengan kesehatan (Machfoedz dkk, 2012).

Kegiatan health education meningkatkan pengetahuan dan kemampuan ibu hamil dalam mengatasi keluhan hemorrhoid yang dialaminya. Apabila pengetahuan ibu hamil baik maka keluhan hemoroidnya akan berkurang dengan metofew Sitz bath tersebut sehingga ibu hamil akan merasa nyaman sehingga meningkatkan kesehatannya dan juga janinnya.

\section{KESIMPULAN}

Berdasarkan hasil penelitian maka dapat ditarik kesimpulan yaitu:

1. Pengetahuan ibu tentang Terapi Sitz Bath di Wilayah Kerja Puskesmas Balong Kabupaten Ponorogo sebelum dilakukan health education sebagian besar yaitu 16 responden $(51,6 \%) \quad$ mempunyai pengetahuan cukup

2. Pengetahuan ibu tentang Terapi Sitz Bath di Wilayah Kerja Puskesmas Balong Kabupaten Ponorogo setelah dilakukan health education sebagian besar yaitu 18 responden $(58,1 \%) \quad$ mempunyai pengetahuan baik.

3. Ada pengaruh health education terhadap pengetahuan ibu tentang Terapi Sitz Bath di Wilayah Kerja Puskesmas Balong Kabupaten Ponorogo dengan $p$ value $0,000 \leq \alpha 0,05$.

\section{SARAN}

Berdasarkan kesimpulan maka saran dalam hasil penelitian ini adalah :

1. Puskesmas Balong 


\section{Jurnal Delima Harapan 2021}

Peningkatan kegiatan health education pada semua ibu hamil tidak hanya pada ibu hamil Trimester 2 dan 3 sehingga sejak awal sudah bisa mengambil tindakan apabila terjadi hemorrhoid

2. Profesi tenaga kesehatan

Salah satu peran tenaga kesehatan adalah sebagai edukator maka hendaknya melakukan health education secara rutin selama pemberian asuhan. Penyuluhan dapat dilakukan secara individu atau berkelompok sehingga sasaran bisa semakin paham.

3. Responden

Ibu hamil hendaknya meningkatkan pengetahuan tentang metode Sits Bath sebagai salah satu upaya penanganan hemorrhoid melalui petugas kesehatan, media massa atau majalah.

4. Peneliti selanjutnya

Penelitian ini dapat dikembangkan dengan menganalisis keefektifan Metode Sitz Bath terhadap penyembuhan hemorrhoid pada ibu hamil.

\section{DAFTAR PUSTAKA}

1. Buntzen S., Christensen P., Khalid A., et al. Diagnosis and treatment of haemorroids. Danish Medical Journal. 2013; 60 (12)B4754 (PubMed)

2. Djumhana. Patogenesis diagnosis dan pengelolaan medik hemorroid. Bagian Ilmu Penyakit Dalam Rumah Sakit Umum Pusat Dr Hasan Sadikin. Bandung: Fakultas Kedokteran Unpad; 2010.
3. Lockhart, Anita L. \& Lyndon S.(2014).Asuhan Kebidanan Masa Nifas Fisiologis dan Patologis.Tangerang:Binarupa Aksara

4. Machfoedz, Suryani, Sutrisno, Santosa. (2005). Pendidikan Kesehatan Bagian Dari Promosi Kesehatan. Yogyakarta: Fitramaya

5. Notoadmojo, (2013). Pendidikan dan Perilaku Kesehatan. Jakarta: Rineka Cipta

6. - (2012). Promosi Kesehatan Teori Dan Aplikasi. Jakarta. Rineka Cipta

7. Nursalam. (2016). Konsep Dan Penerapan Metodologi Penelitian Ilmu Keperawatan. Jakarta: EGC

8. Ojieh AE. Constipation in pregnancy and the effect of vegetable consumption in different socio-economic class in Warri, Delta state.Journal of Medical and Applied Biosciences 2012; 4: 1-6

9. Riwanto Ign. Usus halus, apendiks, kolon, dan anorektum. Dalam: Sjamsuhidajat R, Jong WD, penyunting. Buku Ajar Ilmu Bedah. Edisi ke-3. Jakarta: EGC; 2010. hal. 788-792

10. Setiawan, M. Riza and Rohmani, Afiana and Kurniati, Ika Dyah and Ratnaningrum, Kanti and Basuki, Rochman (2017) BUKU AJAR: ILMU $B E D A H$. Unimus Press, Semarang

11. Trottier M, Erebara A, Bozzo P. Treating constipation during pregnancy. Can Fam Physician 2012; 58(8): 836-8 